\title{
Weekend admission and mortality from acute exacerbations of chronic obstructive pulmonary disease in winter
}

\author{
FJH Brims, A Asiimwe, NP Andrews, D Prytherch, BR Higgins, S Kilburn and AJ Chauhan
}

\begin{abstract}
Historically, acute medical staffing numbers have been lower on weekends and in winter numbers of medical admissions rise. An analysis of acute exacerbations of chronic obstructive pulmonary disease (AECOPD) admissions to Portsmouth Hospitals over a seven-year period was undertaken to examine the effects of admission on a weekend, of winter, and with the opening of a medical admissions unit (MAU). In total, 9,915 admissions with AECOPD were identified. Weekend admissions accounted for 2,071 (20.9\%) of cases, winter accounted for 3,026 (30.5\%) admissions, and 522 (34.4\%) deaths. Adjusted odds ratio (OR) for death on day 1 after winter weekend admission was 2.89 (95\% confidence interval (CI) 1.035 to 8.076). After opening the MAU, the OR for death day 1 after weekend winter admission fell from 3.63 (95\% CI 1.15 to 11.5 ) to 1.65 (95\% CI 0.14 to 19.01 ). AECOPD patients have an increased risk of death after admission over a weekend in winter and this effect was reduced by opening a MAU. These findings have implications for the planning of acute care provision in different seasons.
\end{abstract}

KEY WORDS: chronic obstructive pulmonary disease, mortality, season, weekend, winter

\section{Introduction}

Chronic obstructive pulmonary disease (COPD) is a leading cause of global morbidity and mortality, and the incidence is rising worldwide. It is the fourth main cause of death in the USA. In the UK over 27,000 people died of COPD in 2004, ${ }^{1}$ and in the same year admissions with COPD took up more than one million bed days in England alone.

Over recent years it has been recognised that unplanned hospital admission on a weekend may be associated with increased mortality. This effect has been demonstrated across different countries in a number of acute medical and surgical condi-

FJH Brims, ${ }^{1}$ consultant physician; A Asiimwe, ${ }^{2}$ PhD student; NP Andrews, ${ }^{3}$ consultant physician; D Prytherch, ${ }^{4}$ senior research fellow; BR Higgins, ${ }^{2}$ senior statistician; S Kilburn, ${ }^{2}$ senior lecturer; AJ Chauhan, consultant physician ${ }^{2,3}$

\footnotetext{
${ }^{1}$ Centre for Respiratory Research, University College London

${ }^{2}$ School of Health Sciences and Social Research, University of Portsmouth

${ }^{3}$ Portsmouth Hospitals NHS Trust

${ }^{4}$ Centre for Healthcare Modelling and Informatics, University of Portsmouth
}

tions $^{2,3}$ including myocardial infarction, ${ }^{4,5}$ hip fracture, ${ }^{6}$ stroke, ${ }^{7,8}$ and upper gastrointestinal haemorrhage. ${ }^{9}$ The effect of worse mortality in patients admitted to an intensive care unit on a weekend has also been documented by most, but not all published studies. ${ }^{10-12}$ A hypothesised reason for this 'weekend effect' is lower, and perhaps more junior, staffing levels as well as less access to diagnostic and treatment resources. To date, a link between emergency weekend admission with acute exacerbation of COPD (AECOPD) and a higher risk of death has not been demonstrated, with four previous studies examining COPD (or chronic bronchitis and emphysema) finding no significant differences. ${ }^{2,3,10,13}$

In many temperate countries including Europe and the USA both hospital admission rates, and mortality during admission, increase in winter. ${ }^{14-17}$ Those most at risk are the elderly, and those with respiratory and cardiovascular disease. ${ }^{18-20}$ Over the last 10 years many secondary care facilities in the UK and other European countries have opened dedicated medical admission units (MAUs) in response to the rising emergency medical admissions burden and government targets. Such units have specialist medical staff, with minimal variation in staffing numbers over weekends and holidays, and dedicated access to diagnostic and treatment resources; this has resulted in reports of reduced length of hospital stay and improved crude mortality rates. ${ }^{21,22}$ Medical admissions are rising each year in the $\mathrm{UK},{ }^{23}$ and the time of admission has been shown to be more likely on weekends and out of normal working hours. ${ }^{24}$ The effect of weekends and season (in particular winter) on mortality on MAUs has not been reported.

A retrospective analysis of unplanned admissions with AECOPD to Portsmouth Hospitals NHS Trust was conducted between 1997 and 2004, and the effect of admission on a weekend in winter on mortality was examined. The effect of opening a large MAU within the institution in 2002 was also examined.

\section{Methods}

\section{Data collection}

Data were retrospectively collected on AECOPD inpatients admitted to a large secondary care hospital that serves Portsmouth. Data for all inpatient admissions related to AECOPD as the primary reason of admission (International Classification of Diseases (ICD) 10th Revision, Codes J40-44) to the hospital between January 1997 and December 2004 were 
extracted from the hospital computerised databases. The data were recorded within the first 24 hours of admission. Patient records were matched across databases using a previously described method. ${ }^{25}$

Confirmation of diagnosis of COPD was sought by analysis of patient records, crosschecking with the respiratory department database, spirometric records and patient-related hospital letters.

\section{Outcomes and potential confounders}

The primary outcome of the study was daily death throughout the first week. The following cohorts were compared: admitted on a weekend $v$ weekday, a weekend in winter $v$ weekday in winter, and a weekend in winter pre-MAU $v$ weekday in winter post-MAU.

The 'weekend' was defined as the period from midnight on Friday to midnight Sunday; all other time was defined as 'weekday'. Variation in season admission rates was analysed, and winter defined as November to January; this was based around the three highest monthly admission rates, rather than strict meteorological criteria. 'Pre-' and 'post-' MAU cohorts were defined as before and after 1 October 2002, the date from which the MAU was fully staffed and operational.

Variables extracted from the databases included demographic characteristics and laboratory tests (haematology and biochemistry) which included renal and liver function, arterial blood gases $(A B G)$, systemic inflammation (white cell count (WCC), platelets, C-reactive protein) and cardiac injury (creatinine kinase, aspartate aminotransferase, troponin I). As the performances of the multivariate logistic regression (MLR) models are dependent on missing data, key biochemical and haematological indices were identified as being indicative of a minimum adequate dataset; these included routine biochemistry (eg urea, electrolytes, creatinine) and haematology (haemoglobin, WCC). Patients without these parameters were considered to have incomplete data, and were excluded from MLR analysis. Mortality data (with calculations based on patient data, rather than episodes) was obtained from the NHS Tracing Service and blood test and demographic data from the patient administration system (PAS).

\section{Analysis}

Data were summarised using means and standard deviation (SD) for continuous variables, and frequencies and percentages for categorical variables. The chi-square and Fishers' exact test were used for categorical variables, and Student t-test for continuous variables in an exploratory data analysis to identify possible predictors of outcome. ${ }^{26}$ Analysis was conducted using Stata statistical software (Version 10; STATA Corp, College Station, Texas). To examine risk of death, MLR modelling was then performed using the XTGEE (generalised estimating equations) procedure in Stata; the use of XTGEE accounts for patients with repeated admissions in the cohorts described above; results are expressed as odds ratios (ORs). To test whether admissions were missing randomly, patients were assigned to whether they had missing or complete data, and the association between this variable and all the independent variables was tested. All p-values are two sided, and the term 'significant' refers to a $\mathrm{p}$-value of $<0.05$.

\section{Ethical approval}

The study was given favourable approval by Isle of Wight, Portsmouth and South East Hampshire, UK, Local Ethics Committee (LREC reference 05/Q1701/34).

\section{Results}

\section{Reliability of diagnosis and mortality data}

In total, 9,985 acute emergency admissions for COPD were identified, comprising 6,315 patients during the study period. Seventy admissions for these patients were excluded because these admissions occurred within 21 days of a previous admission, leaving 9,915 admissions for analysis. The overall in-hospital mortality was $14.6 \%(1,516)$.

In total, 1,581 of the $6,315(24.7 \%)$ patients had a diagnosis of COPD confirmed with examination of spirometric records. Of a further 200 patient records randomly selected to confirm admission for AECOPD, all of them had features consistent with a diagnosis of AECOPD (eg clinical examination and radiographic findings), although 61 patients did not have spirometric confirmation either due to death during admission, default from follow-up or no previous or subsequent record of spirometry. A further analysis of 981 patients demonstrated all dates of admission, status or death were consistent in both the NHS Tracing Service and PAS.

\section{Missing data}

Of the total of 9,985 admissions, 3,578 datasets did not fulfil the minimum data requirements, leaving 6,407 admissions with complete data. There was no association demonstrated between missing and complete datasets and all the independent variables. The crude mortality rates in the complete and incomplete datasets were not significant $(632 / 4,111=15.3 \%$ $v 299 / 2,204=13.6 \%, p=0.097)$. There were no clinically significant differences between the two groups (data not provided).

\section{Baseline characteristics}

A summary of baseline characteristics and laboratory results between the two groups is presented in Table 1. Males accounted for $5,572(56.2 \%)$ of the cohort overall. Overall, on a weekend there were fewer admissions via GPs and greater numbers via the emergency department (ED). From 24 blood parameters, admission creatinine and $\mathrm{PaO}_{2}$ were the only blood results that differed between the weekend and weekday groups. 


\section{Sub-cohort comparisons}

As each sub-cohort of interest contained a varying combination of patients, any differences on baseline characteristics between each cohort were further analysed. Table 2 presents the baseline characteristics that differed statistically between each group, non-significant parameters are not provided.

\section{Seasonal variation in AECOPD admissions and deaths}

Table 3 demonstrates the seasonal variance in AECOPD admissions, with the number of deaths occurring during the same three-month period.

\section{Risk of death after admission on a weekend}

Crude overall in-patient mortality comparing weekend versus weekday admission overall in each subcohort of interest were not significantly different (by chi-squared test; data not provided). The risk of death on a daily basis was then analysed using crude and adjusted ORs for the cohorts; data for days 1, 5 and 7 are presented in Table 4 . There were no statistically significant differences in crude or adjusted OR for death on the remaining days in the first week following admission.

\section{Discussion}

This study has demonstrated that in 9,915 admissions, there was an increased risk of death on day 1 after admission on a weekend

Table 1. Baseline comparison of weekday and weekend groups.

\begin{tabular}{|c|c|c|c|c|c|}
\hline & & Weekday & Weekend & & p-value \\
\hline \multicolumn{2}{|l|}{ Overall n (\%) } & $7,844(79.1)$ & $2,071(20.9)$ & & \\
\hline \multicolumn{2}{|l|}{ Mean age (yrs) } & $71.5( \pm 11.9)$ & $71.2( \pm 12.7)$ & & 0.328 \\
\hline \multicolumn{2}{|l|}{ Male sex n (\%) } & $4,377(55.8)$ & $1,197(57.8)$ & & 0.100 \\
\hline \multirow[t]{3}{*}{ Mode of admission $n(\%)$} & Emergency department & $2,869(36.5)$ & $1,183(57.1)$ & & $<0.001$ \\
\hline & GP & $3,445(43.9)$ & $794(38.3)$ & $<0.001$ & \\
\hline & Other & $1,530(19.5)$ & $94(4.6)$ & $<0.001$ & \\
\hline \multicolumn{2}{|l|}{ Mean length of stay (days) } & $8.89( \pm 10.3)$ & $9.30( \pm 12.7)$ & & 0.136 \\
\hline \multirow[t]{3}{*}{ Blood count } & White cell count & $11.5(7.1)$ & $11.8(5.1)$ & $\times 10^{9} / 1$ & 0.101 \\
\hline & Haemoglobin & $13.6(2.0)$ & 13.5 (1.9) & $\mathrm{g} / \mathrm{dl}$ & 0.259 \\
\hline & Platelets & $292.2(111.5)$ & $285.8(99.1)$ & $\times 10^{9} / 1$ & 0.064 \\
\hline \multirow[t]{4}{*}{ Electrolytes } & Sodium & $137.8(4.4)$ & $138.0(4.7)$ & $\mathrm{mmol} / \mathrm{l}$ & 0.395 \\
\hline & Potassium & $4.3(0.6)$ & $4.3(0.5)$ & $\mathrm{mmol} / \mathrm{l}$ & 0.053 \\
\hline & Urea & $8.2(5.4)$ & $7.9(4.6)$ & $\mathrm{mmol} / \mathrm{l}$ & 0.143 \\
\hline & Creatinine & $110.9(74.1)$ & $106.8(53.2)$ & $\mu \mathrm{mol} / \mathrm{l}$ & 0.022 \\
\hline \multirow[t]{5}{*}{ Liver function } & Alkaline phosphatase & $106.2(66.2)$ & $104.9(63.8)$ & IU/I & 0.473 \\
\hline & Total bilirubin & $12.4(9.0)$ & $11.9(7.7)$ & $\mu \mathrm{mol} / \mathrm{l}$ & 0.092 \\
\hline & Aspartate transaminase & $41.1(154.2)$ & $34.4(51.2)$ & $I U / I$ & 0.063 \\
\hline & Total protein & $68.8(7.2)$ & $68.7(7.2)$ & $\mathrm{g} / \mathrm{l}$ & 0.574 \\
\hline & Albumin & $39.2(5.4)$ & $39.3(5.1)$ & $\mathrm{g} / \mathrm{l}$ & 0.388 \\
\hline \multirow[t]{2}{*}{ Cardiac injury } & Creatinine kinase & $159.0(393.1)$ & $164.6(422.0)$ & IU/I & 0.642 \\
\hline & Troponin I & $7.7(10.5)$ & $7.8(17.2)$ & $\mathrm{ng} / \mathrm{ml}$ & 0.967 \\
\hline \multirow[t]{4}{*}{ Others } & D-dimer & $0.9(0.9)$ & $0.9(0.9)$ & $\mu \mathrm{g} / \mathrm{ml}$ & 0.987 \\
\hline & Corrected calcium & $2.3(0.1)$ & $2.3(0.1)$ & $\mathrm{mmol} / \mathrm{l}$ & 0.366 \\
\hline & Glucose & $7.3(3.4)$ & $7.3(3.1)$ & $\mathrm{mmol} / \mathrm{l}$ & 0.907 \\
\hline & C-reactive protein & $67.1(79.1)$ & $68.2(81.6)$ & $\mathrm{mg} / \mathrm{l}$ & 0.662 \\
\hline \multirow[t]{6}{*}{ Arterial gases } & $\mathrm{pH}$ & $7.4(0.1)$ & $7.4(0.1)$ & $\mathrm{pH}$ & 0.759 \\
\hline & $\mathrm{paO}_{2}$ & $11.4(6.1)$ & $12.2(6.8)$ & $\mathrm{kPa}$ & $<0.001$ \\
\hline & Base excess & $1.4(4.8)$ & $1.1(4.9)$ & $\mathrm{mmol} / \mathrm{l}$ & 0.120 \\
\hline & Bicarbonate & 25.6 (3.9) & $25.4(4.0)$ & $\mathrm{mmol} / \mathrm{l}$ & 0.203 \\
\hline & $\mathrm{paCO}_{2}$ & $6.1(2.0)$ & $6.2(2.2)$ & $\mathrm{kPa}$ & 0.246 \\
\hline & Saturation & $92.7(7.3)$ & $93.3(7.1)$ & $\%$ & 0.160 \\
\hline
\end{tabular}

All values presented as mean $(\mp \mathrm{SD})$ unless otherwise stated

Other = accounted for admissions from out patients, hospital at home schemes, inter-specialty and hospital transfers, and unknown/unclassified. 
Table 2. Statistically significant baseline characteristics between sub-cohorts.

\begin{tabular}{|c|c|c|c|c|c|}
\hline Variable & Units & $\begin{array}{l}\text { Winter weekday } \\
\text { Mean (SD) }\end{array}$ & & $\begin{array}{l}\text { Winter weekend } \\
\text { Mean (SD) }\end{array}$ & $p=s$ \\
\hline & & & $n=3,026$ & & \\
\hline Platelets & $\times 10^{9} / 1$ & $288(113)$ & & $271(91.3)$ & 0.05 \\
\hline \multirow[t]{3}{*}{$\mathrm{PaO}_{2}$} & $\mathrm{kPa}$ & $11.1(5.5)$ & & $11.9(6.6)$ & 0.009 \\
\hline & & Winter weekday pre-MAU & & Winter weekend pre-MAU & \\
\hline & & & $n=2121$ & & \\
\hline WCC & $\times 10^{9} / 1$ & $11.3(5.5)$ & & $11.8(5.2)$ & 0.002 \\
\hline \multirow[t]{3}{*}{$\mathrm{PaO}_{2}$} & $\mathrm{kPa}$ & $11.3(6.1)$ & & $12.1(6.9)$ & $<0.001$ \\
\hline & & Winter weekday post-MAU & & Winter weekend post-MAU & \\
\hline & & & $\mathrm{n}=908$ & & \\
\hline $\mathrm{PaO}_{2}$ & $\mathrm{kPa}$ & $11.6(6.0)$ & & $12.2(6.8)$ & 0.035 \\
\hline
\end{tabular}

$\mathrm{MAU}=$ medical assessment unit; $\mathrm{WCC}=$ white cell count.

during winter with AECOPD. This risk has been reduced by the opening of a dedicated MAU. This is the first study to demonstrate such an effect in AECOPD, and the first to examine the effect of season, and local changes in service provision. Furthermore, our methodology is unique in using patient-specific physiological parameters as part of the analysis, as well as allowing any effect of repeated admissions, in a study of this kind. These unique reasons may, in part, account for why other studies have failed to demonstrate such an effect in COPD to date.

Our findings support other recent disease-specific studies that have found comparable results to ours. In stroke, both Saposnik and Hasegawa and colleagues have reported a higher adjusted risk of mortality after admission on a weekend. ${ }^{7,8}$ Foss et al demonstrated a higher adjusted hazard ratio for death at five days following admission over holiday periods (but not weekends) for fractured hip ${ }^{6}$ and, furthermore, demonstrated lower staffing levels at these times. More recently Kostis et al and Cubeddu et al have demonstrated an increased adjusted risk of mortality with acute myocardial infarction at 30 days after weekend admission, ${ }^{4,5}$ and Ananthakrishnan et al have reported a higher odds ratio of mortality on day 1 after weekend admission with nonvariceal upper gastrointestinal bleed. ${ }^{9}$ Throughout all of these studies, the hypothesised reason for this 'weekend effect' is lower staffing levels and perhaps less access to diagnostic and treatment resources during these times. In support for this, Richardson et al recently demonstrated a worse inhospital mortality in an Australian emergency department during overcrowded shifts (but not weekends specifically). ${ }^{27}$ A previous study examining links between mortality and AECOPD in $30 \mathrm{UK}$ hospitals demonstrated that a higher mortality may be associated with lower doctor numbers. ${ }^{28}$ In this study, the busiest period for acute medical and AECOPD admissions over weekends was examined and an increased risk of death on day 1 , which was mitigated by the commission of a MAU, with dedicated specialist
Table 3. Seasonal variation in AECOPD admission and mortality.

$\begin{array}{lcc}\text { Season } & \text { Admissions } \mathbf{n}(\%) & \text { Deaths } \mathbf{n}(\%) \\ \text { Winter } & 3,026(30.5) & 522(34.4) \\ \text { Spring } & 2,473(24.8) & 343(22.6) \\ \text { Summer } & 2,218(24.3) & 296(19.5) \\ \text { Autumn } & 2,198(22.1) & 355(23.4)\end{array}$

staff, and improved access to treatment resources was established. This may in turn allow improved recognition of the critically ill and enhanced local access and expertise to treatments such as non-invasive ventilation.

This 'weekend effect' has important clinical implications: managers and clinicians may be part of a system failing to provide adequate clinical cover for patients over the weekend (and, perhaps out of hours) period. A previous confidential study into medical deaths after acute admissions in three UK hospitals reported that many potentially avoidable deaths happened out of hours and at night. ${ }^{24}$ It is conceivable that having a dedicated team of healthcare workers within one admissions unit, with appropriate access to diagnostic and treatment resources has resulted in the changes in mortality risk demonstrated above. Additionally, one must take account of the significant changes to doctors' working patterns over the last five years within the NHS. This has resulted in the universal adoption of shift patterns incorporating night shifts as well as weekend commitments. This has no doubt resulted in higher staffing levels and less tired health professionals, thus, some of the effect demonstrated above may also be in part due to this. Either way, if the findings of this study are in part due to staffing levels, it is important for healthcare provision, resource and planning. 
While there was a reduction in day 1 mortality following the opening of a MAU within the trust, the adjusted risk on day 5 following a winter weekend admission became significant. Reliable elucidation of the reasons for this are beyond the scope of this study, however it is very likely that on day 5 of an admission most patients would have been moved to a medical ward (the average length of stay on this MAU is 48 hours). Thus this effect may signify issues with staffing levels on the general wards during winter, when bed occupancy may be extremely high. Additionally, the improved pattern of out-of-hours staffing discussed above is likely to be largely reflected in emergency areas, such as the MAU, and not necessarily on general wards. However, it must also be considered that this finding may simply be a spurious statistical result.
On analysis of baseline characteristics between the subcohorts, $\mathrm{PaO}_{2}$ was consistently statistically different between the groups. The difference between the means varied between $0.6-0.8 \mathrm{kPa}$, with the weekend cohort always the higher. It is argued that this is of statistical and not clinical significance because there was no statistical difference between the cohorts in $\mathrm{pH}$, mean $\mathrm{PaCO}_{2}$, or the numbers of those with raised $(>6.5$ $\mathrm{kPa}) \mathrm{PaCO} 2$ between the cohorts (weekday 1,310/7,844 (28\%), weekend 390/2,071 (27.6\%), $\mathrm{p}=0.813)$. Therefore, there is no evidence of differing numbers of those with type II respiratory failure, or indeed any other biochemical or haematological markers of illness severity. The means by which a patient was admitted to hospital differed significantly between the two

\section{Table 4. Crude and adjusted risk of death after weekend admission, the effect of winter and commission of a MAU.}

Weekend admission $(n=9915)$

\section{Crude OR}

$\begin{array}{llll}\text { Day } & \text { Daily mortality } & \text { OR } & \\ & & & \text { Upper } \\ 1 & 59 & 2.249 & 1.334 \\ 5 & 53 & 1.109 & 0.582 \\ 7 & 36 & 1.457 & 0.702\end{array}$
$95 \% \mathrm{Cl}$

Lower
3.849
2.114
3.030

$\mathrm{OR}$

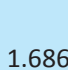

1.349

1.750
Adjusted $O R^{*}$

\begin{tabular}{lll}
\multicolumn{2}{c}{$95 \% \mathrm{Cl}$} & $p=$ \\
Upper & Lower & \\
0.906 & 3.167 & 0.098 \\
0.691 & 2.642 & 0.374 \\
0.749 & 4.128 & 0.195
\end{tabular}

Weekend admission in winter $(n=3026)$

\section{Crude OR}

$\begin{array}{llll}\text { Day } & \text { Daily mortality } & \text { OR } & \\ & & & \text { Upper } \\ 1 & 22 & 2.420 & 1.036 \\ 5 & 21 & 1.399 & 0.894 \\ 7 & 11 & 1.311 & 0.971\end{array}$

$95 \% \mathrm{Cl}$

Lower
5.733
1.902
1.920

0.040

0.485

0.688
OR

2.891

1.981

2.334

\section{Adjusted OR +}

\begin{tabular}{lll}
\multicolumn{2}{c}{$95 \% \mathrm{Cl}$} & $\mathrm{p}=$ \\
Upper & Lower & \\
1.035 & 8.076 & 0.043 \\
0.721 & 5.449 & 0.185 \\
0.518 & 10.513 & 0.270
\end{tabular}

Weekend admission in winter pre MAU $(n=2121)$

\section{Crude OR}

$\begin{array}{ll}\text { Day } & \text { Daily mortality } \\ 1 & 46 \\ 5 & 34 \\ 7 & 29\end{array}$

OR
3.660
0.732
1.830

Upper
1.384
0.160
0.457

$95 \% \mathrm{Cl}$

Lower
9.938
3.349
7.371

$p=$
0.009
0.687
0.391

OR

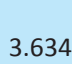

1.007

4.589

\section{Adjusted OR $¥$}

\begin{tabular}{lll}
\multicolumn{2}{c}{$95 \% \mathrm{Cl}$} & $\mathrm{p}=$ \\
Upper & Lower & \\
1.146 & 11.527 & 0.028 \\
0.207 & 4.899 & 0.993 \\
0.742 & 28.362 & 0.101
\end{tabular}

Weekend admission in winter post MAU $(n=908)$

\section{Crude OR}

$\begin{array}{ll}\text { Day } & \text { Daily mortality } \\ 1 & 13 \\ 5 & 19 \\ 7 * * & 7\end{array}$

$\mathrm{OR}$

0.631

2.534

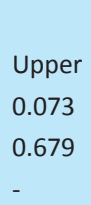

$95 \% \mathrm{Cl}$

Lower
5.409
9.580

$$
\mathrm{p}=
$$

OR

0.673

0.162

0.995

\section{Adjusted OR §}

\begin{tabular}{lll}
\multicolumn{2}{c}{$95 \% \mathrm{Cl}$} & $\mathrm{p}=$ \\
Upper & Lower & \\
0.142 & 19.013 & 0.690 \\
1.164 & 26.657 & 0.032 \\
- & - & 0.995
\end{tabular}

* adjusted for age, sex, creatinine, $\mathrm{paO}_{2} ; \dagger$ adjusted for age, sex, platelets, $\mathrm{paO}_{2} ;$; adjusted for age, sex, $\mathrm{WCC}, \mathrm{paO}_{2} ; \S$ adjusted for age, sex, paO ${ }_{2} ; * *$ data for Day 7 absent due to number in mortality group too low for computation of $\mathrm{OR}$.

$\mathrm{Cl}=$ confidence interval; $\mathrm{MAU}=$ medical assessment unit; $\mathrm{OR}=$ odds ratio. 
groups; with ED as the main route of admission on the weekend, as compared to via a GP during the week. This is an indication of lower levels of access to primary care consultations on a weekend and this effect is likely to be reflected in all emergency medical and surgical conditions in the UK. Regression analysis adjusting for mode of admission failed to influence the likelihood of mortality in this study.

This study was not designed to examine risk of death in AECOPD per se, and therefore the absence of parameters such as inflammatory markers, $\mathrm{pH}$ or $\mathrm{PaCO}_{2}$ from statistical significance should not be of concern. Unfortunately this study is not able to demonstrate why these patients have died, but simply that there is an excess risk of death following admission on a weekend after adjustment for differences in physiological parameters.

In interpreting our findings it is important to recognise some potential limitations of the study. It is plausible that during original data entry the diagnosis may have been inaccurate, or wrongly coded. Data validity was, however, checked by examination of $28.2 \%$ of the cohort, with a maximum potential error rate of just $2.4 \%$. Even if this were the case, misclassification of diagnosis would bias toward the null, as the effect would be reduced. Additionally, public holidays were not included in this calculation, however this bias would once again tend to underestimate any effect.

Nevertheless, despite adjustment for confounding factors including demographic and physiological parameters, a harmful 'weekend effect' for those admitted over winter months in the absence of a dedicated MAU has been demonstrated.

\section{Conclusion}

Emergency admissions to hospitals across the UK are rising by $4-5 \%$ a year. ${ }^{23}$ If the effect demonstrated above is indeed a reflection of lower staffing, diagnostic and treatment assets, and the effect of high numbers of acute admissions on such resources, then this has significant implications for the planning of acute medical care. Staffing and resource levels must reflect the increasing burden of acute medical admissions, and consideration to the provision of extra doctors and healthcare workers during times of excessive burden on local resources should be given.

\section{Funding}

This work was supported by a student bursary (for AA) from the University of Portsmouth, UK.

\section{References}

1 British Thoracic Society. The burden of lung disease, 2nd edn. A statistics report from the British Thoracic Society. London: BTS, 2006.

2 Cram P, Hillis SL, Barnett M, Rosenthal GE. Effects of weekend admission and hospital teaching status on in-hospital mortality. Am J Med 2004;117:151-7.

3 Bell CM, Redelmeier DA. Mortality among patients admitted to hospitals on weekends as compared with weekdays. $N$ Engl J Med 2001;345:663-8.

4 Kostis WJ, Demissie K, Marcella SW et al. Weekend versus weekday admission and mortality from myocardial infarction. $N$ Engl J Med 2007;356:1099-109.
5 Cubeddu RJ, Cruz-Gonzalez I, Kiernan TJ et al. ST-elevation myocardial infarction mortality in a major academic center 'on' -'versus 'off-' hours. J Invasive Cardiol 2009;21:518-23.

6 Foss NB, Kehlet H. Short-term mortality in hip fracture patients admitted during weekends and holidays. Br J Anaesth 2006;96:450-4.

7 Saposnik G, Baibergenova A, Bayer N, Hachinski V. Weekends: a dangerous time for having a stroke? Stroke 2007;38:1211-5.

8 Hasegawa Y, Yoneda Y, Okuda S et al. The effect of weekends and holidays on stroke outcome in acute stroke units. Cerebrovasc Dis 2005;20:325-31.

9 Ananthakrishnan AN, McGinley EL, Saeian K. Outcomes of weekend admissions for upper gastrointestinal hemorrhage: a nationwide analysis. Clin Gastroenterol Hepatol 2009;7:296-302e1.

10 Barnett MJ, Kaboli PJ, Sirio CA, Rosenthal GE. Day of the week of intensive care admission and patient outcomes: a multisite regional evaluation. Med Care 2002;40:530-9.

11 Ensminger SA, Morales IJ, Peters SG et al. The hospital mortality of patients admitted to the ICU on weekends. Chest 2004;126:1292-8.

12 Laupland KB, Shahpori R, Kirkpatrick AW, Stelfox HT. Hospital mortality among adults admitted to and discharged from intensive care on weekends and evenings. J Crit Care 2008;23:317-24.

13 Schmulewitz L, Proudfoot A, Bell D. The impact of weekends on outcome for emergency patients. Clin Med 2005;5:621-5.

14 Curwen M. Excess winter mortality: a British phenomenon? Health Trends 1990;91:169-75.

15 Healy JD. Excess winter mortality in Europe: a cross country analysis identifying key risk factors. J Epidemiol Community Health 2003;57:784-9.

16 Howieson SG, Hogan M. Multiple deprivation and excess winter deaths in Scotland. J R Soc Health 2005;125:18-22.

17 Reichert TA, Simonsen L, Sharma A et al. Influenza and the winter increase in mortality in the United States, 1959-1999. Am J Epidemiol 2004;160:492-502.

18 Wilkinson P, Pattenden S, Armstrong B et al. Vulnerability to winter mortality in elderly people in Britain: population based study. BMJ 2004;329:647.

19 Martinez-Selles M, Garcia Robles JA, Prieto L et al. Annual rates of admission and seasonal variations in hospitalizations for heart failure. Eur J Heart Fail 2002;4:779-86.

20 Aronow WS, Ahn C. Elderly nursing home patients with congestive heart failure after myocardial infarction living in New York City have a higher prevalence of mortality in cold weather and warm weather months. J Gerontol A Biol Sci Med Sci 2004;59:146-7.

21 Moloney ED, Smith D, Bennett K, O'Riordan D, Silke B. Impact of an acute medical admission unit on length of hospital stay, and emergency department 'wait times'. QJM 2005;98:283-9.

22 Moore S, Gemmell I, Almond S et al. Impact of specialist care on clinical outcomes for medical emergencies. Clin Med 2006;6:286-93.

23 Department of Health. The DoH annual report. London: DH, 2007.

24 Seward E, Greig E, Preston S et al. A confidential study of deaths after emergency medical admission: issues relating to quality of care. Clin Med 2003;3:425-34.

25 Prytherch D, Sirl JS, Weaver PC et al. Towards a national clinical minimum data set for general surgery. Br J Surgery 2003;90:1300-5.

26 Hosmer DW, Lemeshow S. Applied logistic regression, 2nd edn. New York: John Wiley \& Sons, 2000.

27 Richardson DB. Increase in patient mortality at 10 days associated with emergency department overcrowding. Med J Aust 2006;184:213-6.

28 Roberts CM, Barnes S, Lowe D, Pearson MG. Evidence for a link between mortality in acute COPD and hospital type and resources. Thorax 2003;58:947-9.

Address for correspondence: Dr F Brims, Room 436, 4th Floor, Rockefeller Building, 21 University Street, London WC1E 6J]. Email: f.brims@ucl.ac.uk 